\title{
How can Cleaner Production practices contribute to meet ISO 14001 requirements? Critical analysis from a survey with industrial companies
}

\author{
José Augusto de Oliveira ${ }^{1}$ - Diogo Aparecido Lopes Silva ${ }^{2,4} \cdot$ Mariana Guardia $^{3,5}$. \\ Lillian do Nascimento Gambi ${ }^{2,4}$ - Otávio José de Oliveira ${ }^{3,5}$ - Aldo Roberto Ometto
}

Received: 19 September 2016/ Accepted: 24 April 2017/Published online: 29 April 2017

(c) Springer-Verlag Berlin Heidelberg 2017

\begin{abstract}
The companies' needs to adopt changes in their way of production to maximize the environmental performance required by their stakeholders, and at the same time, to maximize their economic and market performance, have made them seek for environmental strategies and certifications. In this sense, the Cleaner Production and the Environmental Management System based on ISO 14001 have been, respectively, presented, since the main objective of this research is to identify and analyze Cleaner Production contributions to comply with ISO 14001 requirements. For such, a survey research has been carried out in Brazilian industrial companies certified by ISO 14001. We have identified the main performance factors by leading practices and variables of Cleaner Production that contribute to the compliance with the standard requirements by companies. Thus, it has been noted that Cleaner Production is an important strategy for the preparation of
\end{abstract}

José Augusto de Oliveira

jose.oliveira@sjbv.unesp.br

1 Campus of São João da Boa Vista, São Paulo State University (Unesp), Av. Profa. Isette Corrêa Fontao 505, São João da Boa Vista 13876-750, Brazil

2 Department of Production Engineering, Federal University of São Carlos, Rodovia João Leme dos Santos (SP-264), Km 110, Sorocaba 18052-780, Brazil

3 Department of Production Engineering, School of Engineering of São Carlos, University of São Paulo, Av. Trabalhador Sao-Carlense 400, São Carlos 13566-590, Brazil

4 Institute of Exact and Technological Sciences, Rio Paranaíba Campus, Federal University of Viçosa, Rodovia MG-230 Km 7, Rio Paranaíba - MG, Viçosa 38810-000, Brazil

5 Department of Production Engineering, Faculty of Engineering of Guaratinguetá, São Paulo State University, Av. Pereira da Cunha 333, Guaratinguetá 12516-410, Brazil companies for certification as well as for improving their environmental performance.

Keywords Cleaner Production · ISO 14001 - Compliance . Environmental Management System · Brazilian industrial companies

\section{Introduction}

Environmental Management Systems (EMSs) help organizations manage the environmental effects of their operations in an organized way and provide organizations with structure, procedures and resources for implementing environmental policy, set goals and monitor performance (Arimura et al. 2016). The reasons for implementing an EMS can be related to external factors (i.e., organization's image, market and client-related advantages and demands) or internal factors (i.e., emergency response, improving information flows, employee motivation, waste reduction, increasing operational efficiency, financial and organizational benefits) (Campos 2012).

Since the 1970s, environmental management has become a more interdisciplinary and holistic subject, more focused on encouragement and support rather than enforcement (Barrow 2006), and on the improvement in the efficiency of their production processes (UNEP/UNIDO 2004). Industries began to pursue new technologies to close the circuits of use of materials (Beamon 1999) and facilitate reuse and recycling (Florida 1996), and other practices, which led to the development of the Cleaner Production (CP) strategy.

According to UNEP (1995) "Cleaner Production is the continuous application of an integrated environmental strategy to processes, products and services to increase efficiency and reduce risks to humans and the 
environment." The CP implementation process is commonly divided in 5 steps: (1) planning and organization; (2) pre-assessment; (3) assessment; (4) assessment and feasibility study and (5) implementation and continuation (UNEP/UNIDO 2004). These steps are sequenced according to the phases of Plan, Do, Check and Act (PDCA) cycle.

In a parallel line to promote a common approach to environmental management and help companies measure and demonstrate their environmental responsibility, the International Organization for Standardization (ISO) developed in 1996 what is now the best-known EMS standard worldwide, the ISO 14000 series (Cheremisinoff and Bendavid-Val 2001).The main goal of ISO 14001 standard is to help firms establish a management process, plan and organize operational and administrative activities aimed at the improvement in environmental performance and reduction in environmental impacts.

The EMS based on this standard is also implemented and managed and based on the four phases of the PDCA cycle (Campos 2012). On September 2015, it launched the latest version of the standard, ISO 14001: 2015. As shown in "Appendix," there was an increase in requirements in this latest version of the standard, expanding its scope for greater involvement of senior management, due to the strategic role that the rule assumed, besides the important integration lifecycle perspective the scope of the EMS based on the standard (ISO 14001: 2015) provides.

Some authors discuss the relations between $\mathrm{CP}$ and EMS in companies. Khan (2008) point out that the reasons for implementing an EMS are virtually the same as those for doing CP. Arimura et al. (2016) reinforce this trend especially when enterprises face growing costs for environmental compliance. However, Oliveira et al. (2016) say that $\mathrm{CP}$ and EMS carry different interests to company managers, since they have different focuses and there is no consensus on whether CP or EMS should come first.

$\mathrm{CP}$ tends to be more focused on technologies and human resources (Xiong and Xiong 2010). The practices based only on technology changes are not enough to assure a company's environmental effectiveness in the long run (Cheremisinoff and Bendavid-Val 2001). Additional tools and practices and a well-defined environmental policy are necessary to ensure good environmental performance (Tong et al. 2012). In this sense, EMS, which is a more systematic approach with guidelines on managing complex environmental components, can improve the $\mathrm{CP}$ program (Cheremisinoff and Bendavid-Val 2001).

The EMS can contribute to increase the effectiveness of $\mathrm{CP}$ practices; however, this is not a mandatory situation. Companies can practice $\mathrm{CP}$ without having a formal or certified EMS (Cheremisinoff and Bendavid-Val 2001). In this way, the $\mathrm{CP}$ program has opened the doors for formal EMS. In general, companies aim ISO 14001 certification and $\mathrm{CP}$ adoption for different reasons. EMS certification promotes market benefits and competitiveness for companies, while $\mathrm{CP}$ maximizes their proactive environmental performance.

Even though CP practices are often seen as separated and small component of an EMS, the goal of any EMS is to manage environmental affairs in a cost-effective way, to continually achieve greater degrees of environmental performance, and CP is critical to accomplish this goal (Oliveira et al. 2016). Cheremisinoff and Bendavid-Val (2001) consider that CP must be part of any comprehensive EMS and that the identification of waste minimization and Cleaner Production opportunities is one of the results of implementing an EMS (Oliveira et al. 2016).

From the above, it is possible to note that there are important studies investigating the synergies and contributions between CP and EMS based on ISO 14001. However, there is still no empirical research that identifies if there are, what they are and how the CP practices contribute to the fulfillment of the ISO 14001 requirements for the implementation and certification of companies' EMS.

In this sense, there are two questions: is there any contribution of the CP program to ISO 14001 requirements? What are these contributions and in what degree do they occur? Thus, the aim of this research was to identify and analyze $\mathrm{CP}$ practices contributions to the compliance with ISO 14001 requirements.

After this introduction, the article is structured by Materials and methods presentation; then, results and analysis are discussed; and finally, the conclusion is presented.

\section{Materials and methods}

The research strategy adopted was the survey-an empirical, descriptive and exploratory inquiry that investigates a phenomenon within its real-life context (Forza 2002). According to Jupp (2006), literature review supported the gap, the questionnaire formulation, the hypothesis, the discussions and the conclusions of this study.

The questionnaire was divided into three main sections: characterization of companies; $\mathrm{CP}$ practices and stages; and assessment of CP influence on ISO 14001 EMS requirements. In the paper text only abbreviations of those variables were used.

The requirements of ISO 14001: 2004 are still valid and make up the main body of the new 2015 version of the standard, which makes them relevant to this study and the present, since this study was based on ISO 14001: 2004 and was carried out in 2012.

The answers followed Likert scale pattern where 5 represents "totally agree" and 1 means "totally disagree." 
This is a range of categorical variables (Forza 2002; Hair et al. 2009).

The chosen respondents were EMS Management Representatives (MR), because they probably have more knowledge of ISO 14001 requirements in the organization. According to Forza (2002) and Synodinos (2003), the choice of the respondents is a crucial methodological stage of the survey. Figure 1 presents the methodological flow of this research.

Firstly, the questionnaire was tested with the responses of 2 (two) Environmental Management researchers and 2 (two) MR of randomly chosen enterprises. In a sequence, the questionnaire was sent to all Brazilian industrial companies certified by ISO 14001, according to database of the National Institute of Metrology, Standardization and Industrial Quality (INMETRO 2012). INMETRO is the accrediting official body of ISO 14001 certifications in Brazil.

Some organizations addresses of this database were outdated. So, in 240 certified business units, the questionnaire was sent to 139 enterprises, because those companies had the correct address in INMETRO database. The return portion was 52 (38\%) companies. This number is considered satisfactory to the survey method studies (Forza 2002; Jupp 2006). Of the total, $5.77 \%$ are small businesses, $38.46 \%$ are medium enterprises and $55.77 \%$ are large companies.
The statistical analysis was conducted with the assistance of Statistica and SPSS software. The multivariate and bivariate analyses were applied to the study, because de phenomenon studied is composed by multiple variables. After this stage, the hierarchical cluster analysis method was applied with the purpose of identifying the homogeneity of the cases and variables relationship. The analysis has been processed with the Euclidean distance as a measure of similarity between businesses, and Ward's method was used for connecting groups (Hair et al. 2009).

The questionnaire's level of reliability was estimated by Cronbach's alpha coefficient using Eq. 1:

$\alpha=\frac{k}{k-1}\left[\frac{\sigma_{\tau}^{2}-\sum_{i=1}^{k} \sigma_{i}^{2}}{\sigma_{\tau}^{2}}\right]$

where $\sigma_{i}^{2}$ represents the variance related to each question $i$ $(i=1,2, \ldots, k)$ and $\sigma_{\tau}^{2}$ is the variance of the sum of the answers of each respondent. The generally assumed lower limit for Crombach's alpha is 0.70 and when it comes to exploratory analyses, the value of 0.60 can be assumed (Hair et al. 2009). In this research, the questionnaire presented a high alpha Cronbach value (0.80), indicating that the instrument shows a high degree of reliability.

Then, the degree of relationship between each pair of variables was estimated by the coefficient of Pearson. Pearson correlation coefficient expresses the degree of linear dependence of two variables. This coefficient has
Fig. 1 Methodological flow of research

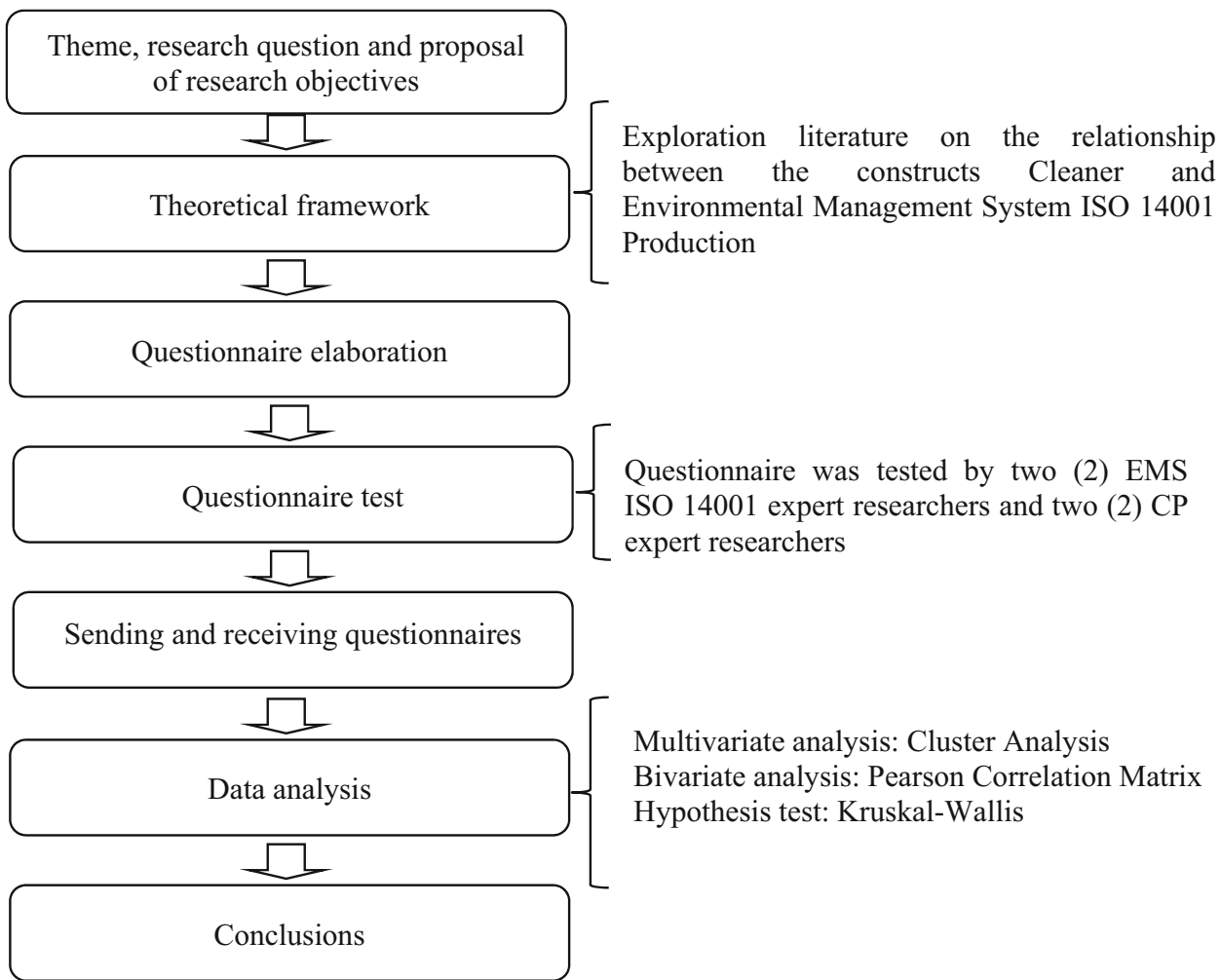


values between -1 and +1 , and is negative when a variable decreases with the increase in another variable, and is positive when a variable increases with the increase in another (Montgomery and Runger 2003).

According to Montgomery and Runger (2003), an important hypothesis test applied in categorical variables is the Kruskal-Wallis. This is a nonparametric method used in a set of samples to test hypotheses of distribution among populations and is used when the variables have no normality, or when the tested groups do not have the same variability (Hair et al. 2009).

The test was conducted considering mean values of specific variables of each block of questions to answer the hypotheses developed for this research. This test is applied considering the alpha value $(p=0.05)$ and its results are arranged as follows:

- If $p>0.05$, Ho is accepted and it is assumed that the data come from the same population; and

- If $p<0.05$, Ho is rejected and it is assumed that the data come from at least two different populations.

The linear regression analysis is recommended to continuous variables (Hair et al. 2009). However, these analyses were applied in the variables of this study to indicate the relationship of the two main sections of the questionnaire (Montgomery and Runger 2003). In a regression analysis considering the correlation coefficient between the means of the last two blocks of the questionnaire, 1 was obtained:

MEMS $=2.01+0.50 \mathrm{MCP}$

The $\mathrm{p}$ value of this analysis is $p=0.000$. This model significantly explains the relationship between $\mathrm{CP}$ stages $(\mathrm{MCP}=$ questionnaire mean of $\mathrm{CP}$ section) and $\mathrm{CP}$ contributions to ISO 14001 requirements $($ MEMS = questionnaire mean of EMS section).

\section{Results and discussion}

Figure 2 presents the variable that measures the $\mathrm{CP}$ adoption level by the organizations.

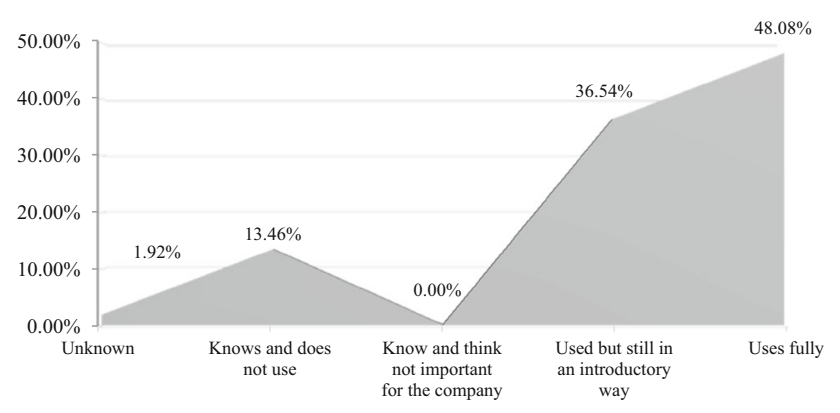

Fig. 2 Cleaner Production level by the organizations
It is possible to see that more than $80 \%$ of the organizations use CP preliminarily or totally. In this context, this sample can be considered appropriate to this research. However, identifying the maturity degree of $\mathrm{CP}$ in these enterprises is not sufficient. In turn, Fig. 3 shows the levels of CP application by Brazilian enterprises certified by ISO 14001.

Figure 3 shows that product modification is not adopted by the companies. In general, it is observed that companies adopt, on average, the three levels of $\mathrm{CP}$ application. However, there are high standard deviation values for internal recycling, technological modification and substitution of raw materials practices, representing heterogeneity in the adoption of these CP practices. On the other hand, there is greater consensus in the adoption of housekeeping and external recycling by companies.

At Level 1 of CP implementation, the most prioritized practices are housekeeping, elimination or minimization of waste in processes and reduction in the use of inputs and raw materials at the source.

On the second level of prioritization of CP application, high values are assigned to the two practices established by UNEP. This scenario shows companies preference for reusing shares of inputs and internal recycling in production processes. This practice is in second position in the levels of CP application list for presenting lower rates of pollution prevention and environmental impacts since the waste have been generated by production processes, but are reused within the processes themselves, so they are still considered good CP practices. A plausible answer for choosing this $\mathrm{CP}$ application level may be related to the fact that it presents high potential for economic recovery in production processes and also avoids the final disposal of waste, minimizing potential environmental impacts resulting from production processes.

It is also observed a high value assigned to the third level of $\mathrm{CP}$ implementation with regard to external waste recycling production processes. The use of production process waste in another production process has great potential for economic return to production as a whole and therefore for the company and also avoids the treatment and disposal of these wastes. It is environmentally less favorable than the above two levels, because it has less potential for pollution prevention and environmental impacts, as it reached no measures focused on the root cause of environmental aspects that originated such waste.

\section{Multivariate and bivariate analyses}

Figure 4 shows the dendrogram containing the structure of groups by the hierarchical cluster analysis method of the companies considered. The organizations are numbered in the abscissa axis. 
Fig. 3 Levels of CP application by Brazilian enterprises certified by ISO 14001
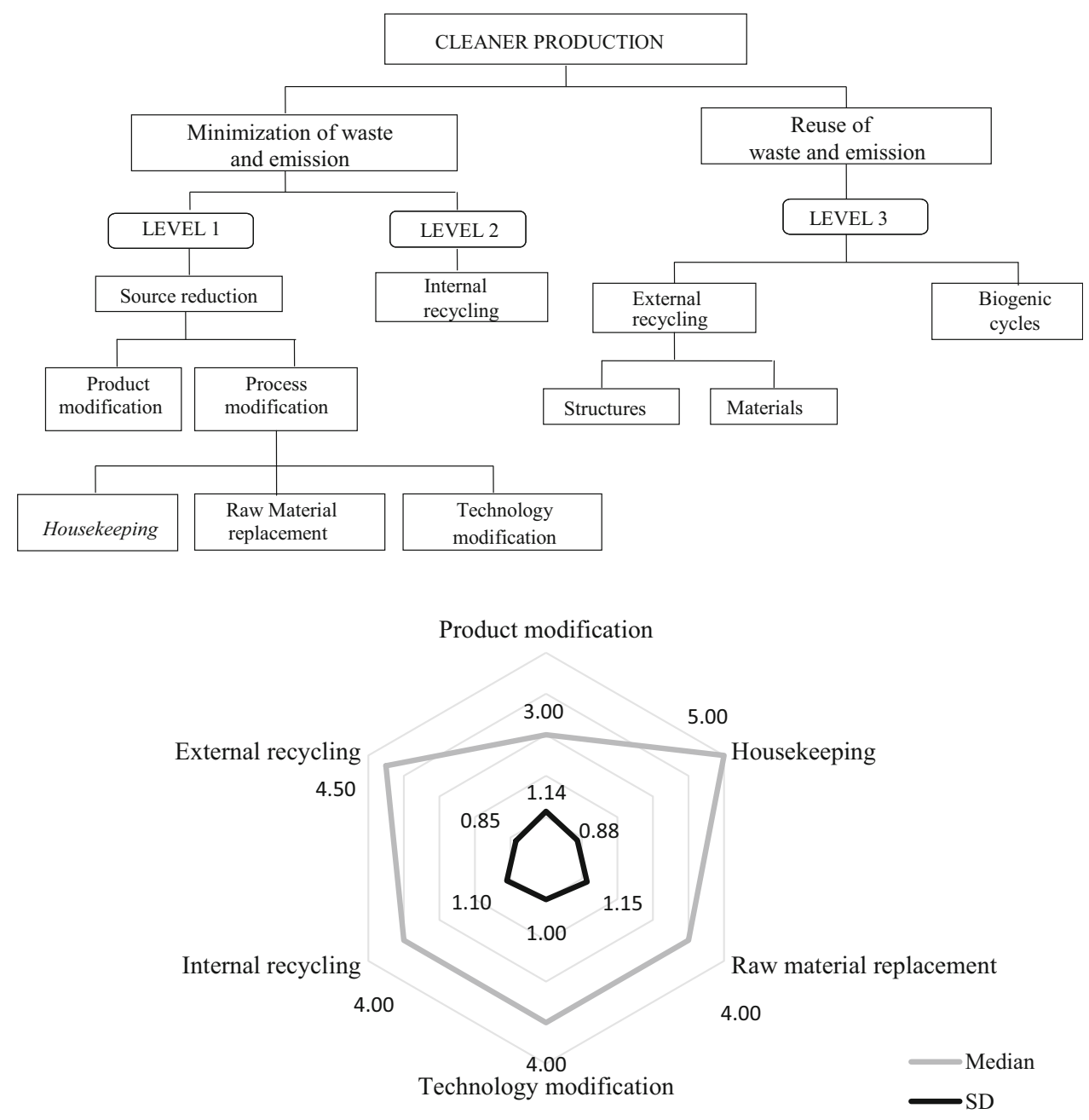

The dendrogram separates the organizations in 4 (four) major groups. Three of them are highlighted (G1, G2 and G3) and the other companies of the survey sample represent the fourth group (G4).

The first group (G1) is formed by organizations of different sizes, and most of them are large enterprises operating in the market for over 26 years. On the average the enterprises of this group export less than $26 \%$ of their billing.

All these organizations have ISO 14001 certification across the plant and needed to hire a professional consultant to implement the EMS, which lasted up to 12 months on average. For this implementation process, the companies of group 1 spent less than U\$ 3,000,000 and adopted the CP still at the introductory level.

The organizations of the second group (G2) did not disclose their billing and size. On average, these companies operate in the market from 26 to 50 years and do not export. The scope of their ISO 14001 certification is total and these organizations did not need to hire external services to implement the EMS. This process lasted less than
12 months and these enterprises spent less than U\$ $3,000,000$ for it.

The third group (G3) is formed by large companies operating in the market for more than 50 years. The organizations of this group export from 50 to $75 \%$ of their billing. All companies obtained the certification in their whole plants and needed to hire external service to implement the EMS. This implementation lasted less than 24 months and the enterprises spent less than U\$3,000,000 in the process.

The other companies formed the fourth group. These enterprises are not described here because the major objective of this analysis is to investigate the behavior of the variables of the cases, as shown in Fig. 5.

The tendency lines presented in Fig. 5 show a homogeneous behavior of variables that characterize the companies. In this sense, this analysis shows that the sample can be adequate to this study.

Table 1 presents the correlation matrix applied to the variables $\mathrm{C} \quad\left(\mathrm{CP}\right.$ stages $\left.^{1}\right)$ and $\mathrm{D}$ (ISO 14001

$\overline{1}$ The list of variables is available in "Appendix". 
Fig. 4 Dendrogram containing the structure of groups by the hierarchical cluster analysis method of the companies considered
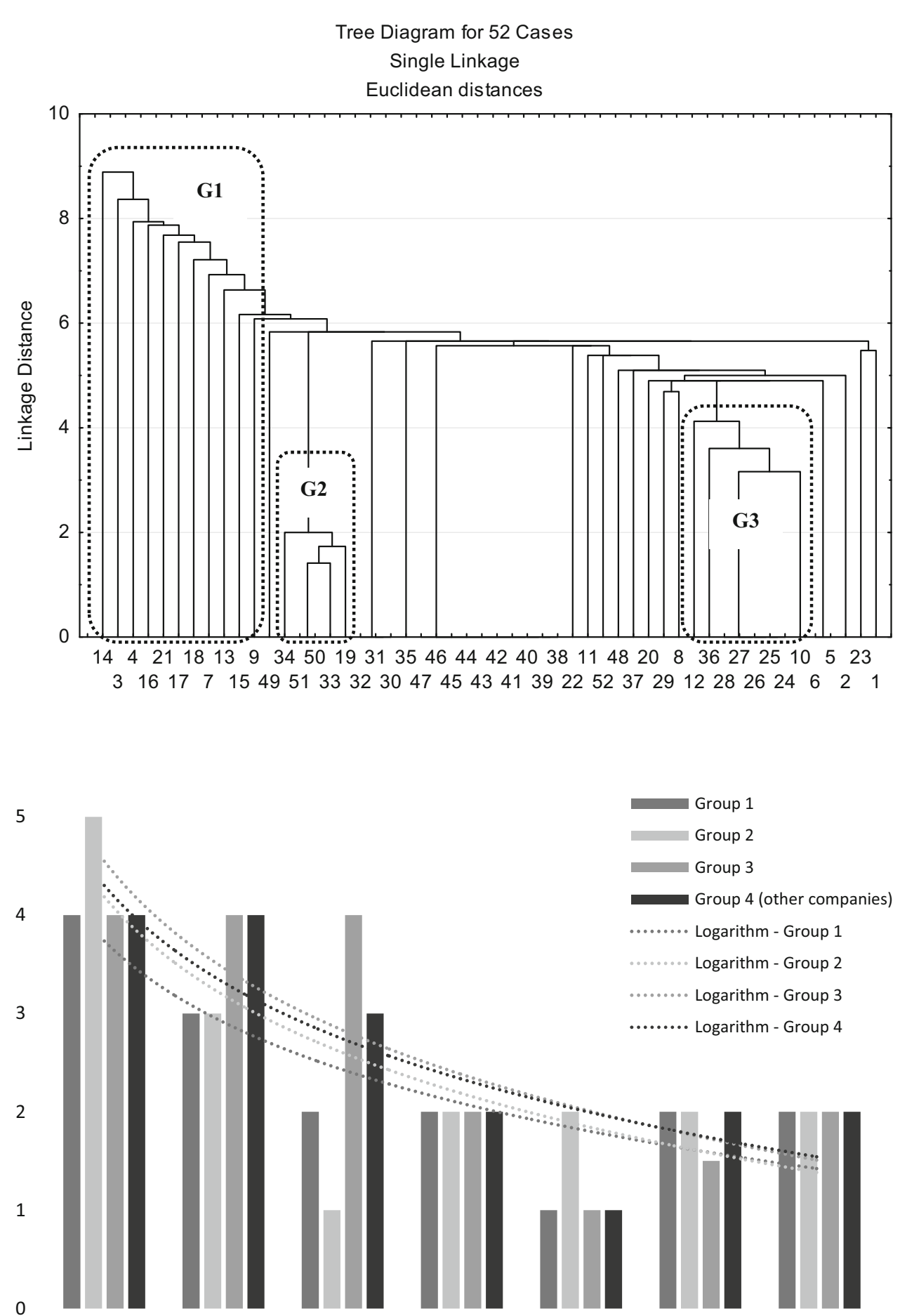

requirements. In fact, the $\mathrm{CP}$ team is responsible for characterizing and planning the general aspects affected by environmental changes in the organization, including ISO 14001 general requirements.

So, it is crucial that the CP team is formed by multidisciplinary professionals, because all requirements involved in the EMS scope need to be contemplated in the environmental changes.
Fig. 5 Behavior of the variables in the sample companies 
Table 1 Correlation matrix

\begin{tabular}{|c|c|c|c|c|c|c|c|c|c|c|c|c|c|c|c|}
\hline & D1 & D2 & D3 & D4 & D5 & D6 & D7 & D8 & D9 & D10 & D11 & D12 & D13 & D14 & D15 \\
\hline $\mathrm{C} 2$ & 0.09 & 0.48 & 0.59 & 0.15 & 0.33 & 0.43 & 0.59 & 0.50 & 0.13 & 0.11 & 0.40 & 0.01 & 0.18 & -0.03 & 0.48 \\
\hline $\mathrm{C} 3$ & 0.51 & 0.49 & 0.37 & 0.38 & 0.62 & 0.37 & 0.39 & 0.39 & 0.27 & 0.22 & 0.41 & 0.20 & 0.23 & 0.18 & 0.43 \\
\hline $\mathrm{C} 4$ & 0.23 & 0.58 & 0.43 & 0.09 & 0.51 & 0.38 & 0.59 & 0.48 & 0.31 & 0.02 & 0.49 & -0.05 & 0.19 & -0.04 & 0.40 \\
\hline C5 & 0.10 & 0.54 & 0.60 & 0.03 & 0.25 & 0.28 & 0.59 & 0.45 & 0.11 & -0.02 & 0.63 & -0.10 & 0.38 & -0.16 & 0.52 \\
\hline C6 & 0.00 & 0.50 & 0.76 & 0.06 & 0.41 & 0.16 & 0.69 & 0.56 & 0.08 & 0.04 & 0.61 & -0.08 & 0.33 & -0.14 & 0.44 \\
\hline C7 & 0.43 & 0.53 & 0.66 & 0.37 & 0.67 & 0.54 & 0.50 & 0.46 & 0.23 & 0.31 & 0.64 & 0.19 & 0.41 & 0.21 & 0.49 \\
\hline $\mathrm{C} 8$ & 0.05 & 0.63 & 0.69 & 0.10 & 0.54 & 0.25 & 0.69 & 0.44 & 0.13 & -0.07 & 0.65 & -0.15 & 0.26 & -0.15 & 0.47 \\
\hline C9 & 0.42 & 0.21 & 0.34 & 0.32 & 0.35 & 0.54 & 0.24 & 0.26 & 0.04 & 0.34 & 0.35 & 0.33 & 0.32 & 0.29 & 0.38 \\
\hline $\mathrm{C} 10$ & 0.35 & 0.19 & 0.41 & 0.33 & 0.31 & 0.46 & 0.25 & 0.29 & 0.00 & 0.38 & 0.38 & 0.27 & 0.36 & 0.24 & 0.37 \\
\hline C11 & 0.24 & 0.41 & 0.51 & 0.22 & 0.35 & 0.41 & 0.45 & 0.30 & 0.05 & 0.12 & 0.57 & 0.04 & 0.38 & 0.02 & 0.36 \\
\hline $\mathrm{C} 12$ & 0.30 & 0.55 & 0.56 & 0.24 & 0.37 & 0.45 & 0.59 & 0.52 & 0.21 & 0.17 & 0.62 & 0.06 & 0.33 & 0.12 & 0.62 \\
\hline C13 & 0.29 & 0.60 & 0.57 & 0.30 & 0.49 & 0.41 & 0.61 & 0.49 & 0.19 & 0.13 & 0.64 & 0.03 & 0.31 & 0.13 & 0.57 \\
\hline C14 & 0.36 & 0.61 & 0.50 & 0.29 & 0.53 & 0.43 & 0.58 & 0.43 & 0.20 & 0.12 & 0.60 & 0.03 & 0.27 & 0.15 & 0.52 \\
\hline C15 & 0.46 & 0.63 & 0.49 & 0.39 & 0.53 & 0.41 & 0.49 & 0.35 & 0.23 & 0.14 & 0.61 & 0.04 & 0.32 & 0.19 & 0.49 \\
\hline C16 & 0.37 & 0.61 & 0.61 & 0.32 & 0.55 & 0.47 & 0.71 & 0.59 & 0.28 & 0.26 & 0.60 & 0.15 & 0.25 & 0.22 & 0.67 \\
\hline $\mathrm{C} 17$ & 0.35 & 0.62 & 0.54 & 0.27 & 0.49 & 0.36 & 0.59 & 0.42 & 0.22 & 0.10 & 0.60 & 0.02 & 0.25 & 0.14 & 0.54 \\
\hline C18 & 0.34 & 0.58 & 0.50 & 0.41 & 0.49 & 0.55 & 0.56 & 0.48 & 0.21 & 0.22 & 0.58 & 0.05 & 0.26 & 0.15 & 0.49 \\
\hline C19 & 0.31 & 0.60 & 0.76 & 0.35 & 0.53 & 0.48 & 0.49 & 0.51 & 0.36 & 0.29 & 0.74 & 0.20 & 0.53 & 0.28 & 0.69 \\
\hline $\mathrm{C} 20$ & 0.04 & 0.52 & 0.56 & 0.03 & 0.29 & 0.32 & 0.77 & 0.63 & 0.34 & 0.05 & 0.58 & -0.03 & 0.23 & -0.06 & 0.59 \\
\hline $\mathrm{C} 21$ & -0.08 & 0.42 & 0.68 & 0.02 & 0.25 & 0.33 & 0.63 & 0.53 & 0.22 & 0.09 & 0.65 & -0.10 & 0.33 & -0.13 & 0.49 \\
\hline $\mathrm{C} 22$ & -0.23 & 0.25 & 0.47 & -0.04 & 0.30 & 0.19 & 0.46 & 0.30 & 0.13 & 0.02 & 0.38 & -0.18 & 0.11 & -0.18 & 0.22 \\
\hline $\mathrm{C} 23$ & 0.37 & 0.04 & 0.05 & 0.36 & 0.35 & 0.47 & 0.14 & 0.40 & 0.45 & 0.46 & 0.04 & 0.53 & 0.19 & 0.44 & 0.36 \\
\hline $\mathrm{C} 24$ & 0.21 & 0.44 & 0.35 & 0.14 & 0.32 & 0.23 & 0.51 & 0.38 & 0.58 & 0.07 & 0.34 & 0.15 & 0.21 & 0.11 & 0.49 \\
\hline $\mathrm{C} 25$ & 0.30 & 0.66 & 0.48 & 0.19 & 0.40 & 0.21 & 0.53 & 0.27 & 0.27 & -0.10 & 0.63 & -0.07 & 0.26 & -0.02 & 0.44 \\
\hline $\mathrm{C} 26$ & 0.00 & 0.48 & 0.49 & -0.15 & 0.23 & 0.07 & 0.66 & 0.37 & 0.40 & -0.16 & 0.45 & -0.18 & 0.15 & -0.18 & 0.35 \\
\hline $\mathrm{C} 27$ & 0.23 & 0.41 & 0.38 & 0.25 & 0.29 & 0.28 & 0.48 & 0.48 & 0.50 & 0.20 & 0.40 & 0.24 & 0.34 & 0.16 & 0.49 \\
\hline $\mathrm{C} 28$ & 0.06 & 0.50 & 0.36 & -0.05 & 0.14 & 0.09 & 0.54 & 0.23 & 0.38 & -0.13 & 0.41 & -0.17 & 0.08 & -0.19 & 0.35 \\
\hline $\mathrm{C} 29$ & 0.33 & 0.77 & 0.61 & 0.25 & 0.49 & 0.30 & 0.60 & 0.49 & 0.34 & 0.00 & 0.75 & -0.07 & 0.32 & 0.04 & 0.58 \\
\hline $\mathrm{C} 30$ & 0.20 & 0.68 & 0.59 & 0.18 & 0.41 & 0.30 & 0.71 & 0.55 & 0.27 & 0.06 & 0.67 & -0.02 & 0.32 & 0.02 & 0.59 \\
\hline C31 & 0.56 & 0.70 & 0.51 & 0.47 & 0.58 & 0.47 & 0.49 & 0.55 & 0.30 & 0.31 & 0.63 & 0.31 & 0.40 & 0.35 & 0.68 \\
\hline
\end{tabular}

The improvement tendency of EMS is expected by the general requirements and the organization must plan and implement ways to improve the environment performance. In this scenario, CP can significantly contribute to this objective.

\section{Environmental Policy (requirement 4.2)}

The identification and classification of $\mathrm{CP}$ priorities (C8), preliminary assessment (C13), technical assessment (C14), economic assessment (C15), environmental assessment (C16), selection of CP options (C17) and systematization of CP opportunities (C19) influence the environmental policy (D2) corresponding to the requirement 4.2 of the standard. In this sense, the planning, assessment and selection of $\mathrm{CP}$ options are relevant to the environmental policy preparation because the major environmental impacts in the production of the enterprises must be included in the very important requirement of ISO 14001 that demonstrates the environmental conduct of the companies to stakeholders.

These CP stages form part of the planning of this environmental strategy and contribute significantly to the 4.2 ISO 14001 requirement, just as well the monitoring (C30) and sustaining (C31) of CP options planned for the implementation in the next stage of continuous improvement. Housekeeping (C25) and external recycling (C29) also contribute to the environmental policy. Although they are CP practices, they are directly related to the commercial strategy of companies, in terms of both improving the 
overall organization and the good practices presented to the market.

Correlation scores with minor charges were observed once in more than two types of $\mathrm{CP}$ contribution to the environmental policy. Firstly the goal establishment (C4), identification of barriers ( $\mathrm{C} 5$ ), flowchart use in production process (C6), analysis of inputs and outputs (C7), criteria establishment for the selection of CP opportunities (C12) and planning of $\mathrm{CP}$ practices $(\mathrm{C} 18)$ are all stages of the $\mathrm{CP}$ planning. These stages must be integrated in the environmental policy and in the EMS manual, because they can maximize the efficiency of this crucial phase for the organization to achieve the environmental goals proposed in the EMS.

Secondly the continuous practices of waste minimization (C20) and the reuse system of wastes (C28) are very important for EMS to effectively maximize performance and gains.

\section{Environmental Aspects identification and management (requirement 4.3.1)}

The identification of barriers (C5), flowchart elaboration to CP opportunities identification (C6), inputs and outputs analysis of production process (C7), identification and classification of $\mathrm{CP}$ implementation priorities (C8), environmental assessment (C16), systematization of CP opportunities (C19), continued actions to reduce the use of inputs and raw materials at the source $(\mathrm{C} 21)$ and external recycling (C29) assist the (D3) corresponding to the environmental aspects identification and management (requirement 4.3.1).

Correlations with lowest value are: C2 (commitment from top management), C11 (identification and classification of CP opportunities), C12 (establishment of criteria for selection of CP options), C13 (preliminary assessment), C14 (technical assessment), C17 (selection of CP opportunities according to assessments), C18 (planning of $\mathrm{CP}$ practices), C20 (continued actions to eliminate or minimize waste in the production process), $\mathrm{C} 30$ (monitoring of $\mathrm{CP}$ practices) and $\mathrm{C} 31$ (sustaining of $\mathrm{CP}$ practices).

All these CP stages form part of the analysis and studies of environmental impacts, which in turn requires the identification and management of environmental aspects. In this way, the appropriate implementation of these $\mathrm{CP}$ stages can be a good practice for compliance with requirement 4.3 .1 by organizations adopting the $C P$.

\section{Legal requirements (requirement 4.3.2)}

There is no significant contribution of CP to the legal requirements of ISO 14001, due to the proactive conduct of CP. Companies adopt $\mathrm{CP}$ in their production aiming at improving their environmental and economic performance. On the other hand, the $\mathrm{CP}$ can contribute to reduce environmental liability and environmental costs for the organizations to achieve legal requirements, but in the specific case of legal requirements of ISO 14001, this correlation was not observed.

Establishment and achievement of objectives, goals and environmental programs (requirement 4.3.3)

In another analysis, the eco-team formation (C3) and inputs and outputs analysis of the production process (C7) contribute to the establishment and achievement of objectives, goals and environmental programs (D5) corresponding to the requirement 4.3 .3 of ISO 14001 standard.

This correlation is highly intuitive. The CP eco-team should always know the inputs and outputs of the enterprise production process in order to plan required measures to face major environmental problems.

Another correlation with low value was observed. The establishment of goals and targets for CP (C4), identification and priority ranking in $\mathrm{CP}$ implementation (C8), technical assessment of CP options (C14), economical assessment of CP options (C15), environmental assessment of CP options (C16), a systematic procedure for identification of CP opportunities (C19) and support of CP shares or continuous improvement (C31), when practiced, already meet the objectives and targets of ISO 14001.

\section{Allocation of resources, roles, responsibilities and authorities turned to EMS (requirement 4.4.1)}

The analysis of inputs and outputs of materials in production processes for identification of $\mathrm{CP}$ opportunities (C7) and implementation plan for CP options (C18) are highly required $\mathrm{CP}$ activities to the division and allocation of resources to implement new options to maximize the environmental performance of production.

\section{Employees' competence, training and awareness in relation to EMS (requirement 4.4.2)}

ISO 140014.4 .2 requirement refers to competence, training and workers' awareness (D7) of EMS. This requirement can be sustained by preparing a flowchart for CP opportunities identification (C6), identification and classification of CP implementation priorities (C8), Preliminary Evaluation (C13), environmental evaluation (C16), continued actions to eliminate or minimize waste in production process (C20), continued actions to reduce the use of inputs and raw materials at the source $(\mathrm{C} 21)$, raw material replacement (C26), external recycling (C29) and monitoring of $\mathrm{CP}$ practices (C30).

It can be observed that these $\mathrm{CP}$ practices promote more involvement of employers with environmental practices. In 
this way, collaborators become more prone to comply with EMS and ISO 14001 objectives and demands, as well as to meet EMS reporting and auditing obligations.

This ISO 14001 requirement is highly benefited with $\mathrm{CP}$, even with minor contributions. In this case we can observe the contribution of management commitment to $\mathrm{CP}$ implementation (C2), establishment of goals and targets for CP (C4), study to identify possible barriers for $\mathrm{CP}$ implementation (C5), analysis of inputs and outputs of materials in production processes for identification of $\mathrm{CP}$ opportunities (C7), establishment of criteria for selection of CP options (C12), technical assessment of CP options (C14), selection of opportunities, according to the feasibility analysis, CP options (C17), a plan for implementation of CP options (C18), modifications in the process or part of it to minimize environmental impacts (C24), housekeeping (C25) and waste reuse system of production (C28).

All these CP practices are carried out by employers actually involved in the production and the environmental changes in the organization. The CP eco-team is formed by multidisciplinary persons and this is an essential instrument to define competence, training and awareness of employees in relation to the EMS.

\section{Communications and environmental documentation (requirements 4.4.3, 4.4.4 and 4.4.5)}

Communications and documentation (D8), corresponding to requirements 4.4.3, 4.4.4 and 4.4.5 of ISO 14001 standard, are sustained by the continued actions to eliminate or minimize waste in the production process (C20). In fact, these actions' systematization contributes to disseminate environmental practices inside and outside the company. In addition, the formalized CP practices' implementation plan meets large part of EMS documentation.

There are also other contributions of CP to this ISO 14001 requirement with lowest value. The management commitment to the implementation of CP (C2), establishment criteria for selection of CP options (C12), environmental assessment of $\mathrm{CP}$ options (C16), systematic procedure for identification of $\mathrm{CP}$ opportunities (C19), continued actions to reduce the use of inputs and raw materials at the source (C21), monitoring of performance of CP shares after its implementation (C30) and continuous improvement (C31) contribute to the documentation and communication of environmental gains and challenges of the organization.

\section{Operational control (requirement 4.4.6)}

The modifications practiced in the process or part of it to minimize environmental impacts (C24) and technology modification to minimize environmental impacts (C27) contribute to the operational control, because these $\mathrm{CP}$ practices are closely linked to the work routine of production lines and cells. In this sense, when the company uses these $\mathrm{CP}$ stages, consequently the operational control will be improved and the requirement 4.4 .6 can be achieved.

\section{Preparation and response to emergencies (requirement} 4.4.7)

There is not a significant contribution of CP to the preparation and response to emergencies of ISO 14001. The CP is not applied to emergencies, due their preventive character rather than corrective. In this case, there is no contribution of CP to ISO 14001, because emergencies would need to be planned for specific and punctual situations.

\section{Monitoring and measurement of environmental aspects (4.5.1 requirement)}

The environmental aspects monitoring and measure (D11) are similar to the environmental aspects identification and management requirement of ISO 14001 standard (D3). However, the first refers to the execution stage while the second refers to the planning stage of EMS. Large part of correlations observed in variable D3 can be noted in variable (D11).

The environmental aspects monitoring and measure (D11) is significantly fostered by the following CP practices: identification of barriers (C5), flowchart preparation to $\mathrm{CP}$ opportunities identification (C6), inputs and outputs analysis of production process (C7), identification and classification of CP implementation priorities (C8), establishment of criteria for selection of CP options (C12), preliminary assessment (C13), technical assessment of $\mathrm{CP}$ options (C14), economic assessment (C15), environmental assessment of CP options (C16), selection of opportunities, according to the feasibility analysis (C17), systematization of CP opportunities (C19), continued actions to reduce the use of inputs and raw materials at the source (C21), housekeeping (C25), external recycling (C29), monitoring of $\mathrm{CP}$ practices $(\mathrm{C} 30)$ and sustaining of $\mathrm{CP}$ practices $(\mathrm{C} 31)$.

The environmental aspects monitoring and measure is still benefited by the identification and classification of opportunities $\mathrm{CP}(\mathrm{C} 11)$, the plan for implementation of $\mathrm{CP}$ options $(\mathrm{C} 18)$ and continued actions to eliminate or minimize waste in production process $(\mathrm{C} 20)$.

This is another ISO 14001 requirement that is highly benefited by $\mathrm{CP}$ practices, because $\mathrm{CP}$ is focused in the root cause of environmental impacts of production. So, by preventing environmental impacts, employers and other resources are prepared to control environmental aspects. 


\begin{tabular}{|c|c|c|}
\hline Cleaner Production & A & ISO 14001 requirements \\
\hline $\begin{array}{l}\text { - Eco-team } \\
\text { - CP sustaining practices }\end{array}$ & \multirow{5}{*}{ Plan } & - General requirements \\
\hline $\begin{array}{l}\text { - Identification and Classification of CP priorities } \\
\text { - Preliminary assessment } \\
\text { - Technical Evaluation } \\
\text { - Economic Assessment } \\
\text { - Environmental Assessment } \\
\text { - Selection of the CP options } \\
\text { - Systematization of CP opportunities }\end{array}$ & & - Environmental policy \\
\hline \multirow[t]{2}{*}{$\begin{array}{l}\text { - Identification of CP opportunities and barriers } \\
\text { - Inputs and Outputs Analysis of the Production } \\
\text { Process } \\
\text { - Identification and classification of CP } \\
\text { implementation priorities } \\
\text { - Environmental Assessment } \\
\text { - Systematization of CP opportunities identification } \\
\text { - Continued Actions to reduce the use of inputs and } \\
\text { raw materials at the source }\end{array}$} & & $\begin{array}{l}\text { - Identifying and managing } \\
\text { environmental aspects }\end{array}$ \\
\hline & & - Legal requirements \\
\hline $\begin{array}{l}\text { - Eco-team formation } \\
\text { - Inputs and Outputs Analysis of the Production } \\
\text { Process }\end{array}$ & & $\begin{array}{l}\text { - Establishment and } \\
\text { achievement of objectives, } \\
\text { goals and environmental } \\
\text { programs }\end{array}$ \\
\hline $\begin{array}{l}\text { - Inputs and Outputs Analysis of the Production } \\
\text { Process } \\
\text { - Plan for implementation of CP options }\end{array}$ & \multirow{5}{*}{ Do } & $\begin{array}{l}\text { - Resources, functions, } \\
\text { responsibilities and authorities }\end{array}$ \\
\hline $\begin{array}{l}\text { - Flowchart preparation for CP opportunities } \\
\text { identification } \\
\text { - Identification and classification of CP } \\
\text { implementation priorities } \\
\text { - Preliminary Assessment } \\
\text { - Environmental Assessment } \\
\text { - Continued Actions to Eliminate or Minimize } \\
\text { Waste in the Production Process } \\
\text { - Continued Actions to reduce the use of inputs and } \\
\text { raw materials at the source } \\
\text { - Raw Material Replacement } \\
\text { - Monitoring of CP practices }\end{array}$ & & $\begin{array}{l}\text { - Competence, training and } \\
\text { awareness }\end{array}$ \\
\hline $\begin{array}{l}\text { - Continued Actions to Eliminate or Minimize } \\
\text { Waste in the Production Process } \\
\text { - Establishment of criteria for selection of CP } \\
\text { options } \\
\text { - Environmental assessment of CP options } \\
\text { - Systematic procedure for identification of CP } \\
\text { opportunities } \\
\text { - Continued Actions to reduce the use of inputs and } \\
\text { raw materials at the source } \\
\text { - Monitoring the performance of CP }\end{array}$ & & $\begin{array}{l}\text { - Communication } \\
\text { - Documentation } \\
\text { - Documentation control }\end{array}$ \\
\hline \multirow[t]{2}{*}{$\begin{array}{l}\text { - Modifications practiced in the process or part of it } \\
\text { to minimize environmental impacts } \\
\text { - Technology modification to minimize } \\
\text { environmental impacts }\end{array}$} & & - Operational control \\
\hline & & $\begin{array}{l}\text { - Preparation and response to } \\
\text { emergencies }\end{array}$ \\
\hline
\end{tabular}

Fig. 6 CP main contributions for organizations to meet ISO 14001 requirements 


\begin{tabular}{|c|c|c|}
\hline $\begin{array}{l}\text { - Flowchart elaboration to CP opportunities } \\
\text { identification } \\
\text { - Identification of CP opportunities and barriers } \\
\text { - Inputs and Outputs Analysis of the Production } \\
\text { Process } \\
\text { - Establishment of criteria for the selection of CP } \\
\text { options } \\
\text { - Preliminary Assessment } \\
\text { - Technical assessment of CP options } \\
\text { - Economic Assessment } \\
\text { - Environmental assessment } \\
\text { - Systematization of CP opportunities } \\
\text { - Continued Actions to reduce the use of inputs and } \\
\text { raw materials at source } \\
\text { - Housekeeping } \\
\text { - Monitoring of the CP practices } \\
\text { - Sustaining of the CP practices }\end{array}$ & \multirow[t]{4}{*}{ Check } & $\begin{array}{l}\text { - Monitoring and measurement } \\
\text { of environmental aspects }\end{array}$ \\
\hline \multirow[t]{3}{*}{$\begin{array}{l}\text { - Modifications in the product to minimize } \\
\text { environmental impacts }\end{array}$} & & $\begin{array}{l}\text { - Treatment of } \\
\text { nonconformities, corrective and } \\
\text { preventive action }\end{array}$ \\
\hline & & $\begin{array}{l}\text { - Control of environmental } \\
\text { records }\end{array}$ \\
\hline & & - Internal audit \\
\hline $\begin{array}{l}\text { - Establishment of criteria for selection of CP } \\
\text { options } \\
\text { - Environmental Assessment } \\
\text { - Systematization of CP opportunities }\end{array}$ & Act & - Management review \\
\hline - Sustaining of CP practices & & \\
\hline
\end{tabular}

Fig. 6 continued

\section{Treatment of nonconformities, corrective and preventive action (requirement 4.5.3)}

Modifications in product to minimize environmental impacts (C23) is the only correlation observed with nonconformities treatment (D12). In fact, nonconformities are very focused on products.

\section{Control of environmental records (requirement 4.5.4)}

There is no significant contribution of $\mathrm{CP}$ to the control of environmental records of ISO 14001. CP is an applied strategy and even though projects and actions must be recorded, ISO 14001 record control is specific to the norm and must be done with standardization. In this sense, the organization can customize the record control with one single process.

\section{Internal audit (requirement 4.5.5)}

There is no significant contribution of CP to ISO 14001 Internal audit. In fact, $\mathrm{CP}$ is not auditable and does not require an audit, because $\mathrm{CP}$ practices are focused on punctual objectives of the organization and are not performed in a systematic way. However, if CP practices are integrated with EMS objectives, this contribution can be strengthened.

\section{Management review (requirement 4.6)}

Finally, variable D15, representing the critical analysis by management (requirement 4.6), is assisted by the establishment of criteria for selection of CP options (C12), environmental assessment (C16), systematization of $\mathrm{CP}$ opportunities (C19) and sustaining of CP practices (C31).

With lower level of contribution, the management review is benefited by the study to identify possible barriers for implementation of CP (C5), primary and general assessment of CP options (C13), technical assessment of $\mathrm{CP}$ options (C14), selection of opportunities, according to the feasibility analysis, CP options (C17), continuous actions of disposal or waste minimization in production process $(\mathrm{C} 20)$, practice of outside recycling efforts to the production process $(\mathrm{C} 29)$ and monitoring the performance of $\mathrm{CP}$ shares after its implementation (C30).

These CP practices show adequate information about environmental impacts of organizations and their production process to the management. Therefore, the 
management may count on sufficient information to plan the next stage to the improvement and assess and plan corrective actions.

All these $\mathrm{CP}$ activities can inform the high management the main gains and future objectives to maximize the organization environmental performance. Figure 6 summarizes CP main contributions for organizations to meet ISO 14001 requirements.

\section{Hypothesis test}

Four research hypotheses were tested, based on theoretical propositions identified in the literature and outlined in the paper introduction. The hypotheses test was carried out using the Kruskal-Wallis test and represents the four important contributions of CP to ISO 14001 EMS. For each hypothesis, a null hypothesis was formulated, as follows:

H1 Companies that adopt the CP more intensely tend to get ISO 14001 certification in full scope of its EMS.

Depending on the value $p=0.00$, do not reject it $\mathrm{H} 1$ (null). Thus, it can be considered that companies that adopt $\mathrm{CP}$ practices more intensely in different levels of priority, have greater environmental maturity and are more capable of achieving ISO 14001 certification in its full scope. One can observe that in this regard companies that practice $\mathrm{CP}$ more effectively are relatively closer to EMS reality and the compliance with ISO 14001 requirements.

H2 Companies that adopt CP more intensely do not need external advice to implement their EMSs according to ISO 14001 requirements.

Since $p=0.23$, i.e., $p>0.05$, reject H0. Thus, it is not possible to say that companies that adopt $\mathrm{CP}$ more intensely tend to dispense with external consulting services to adapt their EMS to ISO 14001 requirements. In fact, CP contributes greatly to the fulfillment of most of ISO 14001: 2004 requirements. However, there are specific requirements of the standard related to legal compliance, preparation and response to emergencies, record of environmental controls, internal audit, among other formalities and documentations not covered by the CP scope. Thus, companies still end up depending on a specialized service to suit the bureaucratic requirements of the standard.

H3 Companies that adopt the CP more intensely tend to take less time to adequate their process to ISO 14001 requirements.

The Kruskal-Wallis test for hypothesis (3) three resulted in a value of $p=0.03(p<0.05)$. Thus, it is possible to accept $\mathrm{HO}$; that is, it can be considered that companies that adopt the CP more effectively tend to need less time to fit their processes to the ISO 14001 requirements. This hypothesis suggests that, operationally, companies that adopt $\mathrm{CP}$ are more suitable for the prevention and control of environmental aspects and impacts, and this is a crucial point for the EMS, and companies can then focus on the formalization of their processes to ISO 14001 requirements, spending less time for it.

H4 Companies that adopt the CP more intensely tend to invest less capital to adequate their process to ISO 14001 requirements.

The result of the test of hypothesis (4) four was $p=0.31$, i.e., $p>0.05$. Thus, the $\mathrm{H} 0$ can be rejected, which indicates that there is not a direct relationship in reducing capital investment for adaptation to ISO 14001 requirements for companies that adopt $\mathrm{CP}$ more effectively. In fact, a significant part of the investment to EMS implementation based on ISO 14001 corresponds to hiring consultants (hypothesis 2), training and operational and documentary controls that are not covered by the CP operation.

It is observed from the identified correlations and tested hypotheses that there is loss of environmental effectiveness and capabilities in the separate operation of CP and EMS by companies. One has to consider that the integration of CP with EMS represents an important strategy for businesses to maximize their environmental and operating performance, since $\mathrm{CP}$ contributes significantly to meet ISO 14001 requirements.

Added to this, this integration would make it possible to avoid great loss of human, operational and financial resources, and would significantly increase the companies' economic performance through the integration of $\mathrm{CP}$ to EMS.

\section{Conclusions}

In general, CP use to meet ISO 14001 requirements can be a good opportunity for organizations to adopt a preventive and proactive conduct in their EMS and their business.

Based on the results presented, we concluded that companies that adopt the $\mathrm{CP}$ more intensely are more prepared to meet ISO 14001 requirements and obtain certification. It can be considered that EMS and CP management has to be made in an integrated manner, increasing the efficiency of resources used and the effectiveness of their results.

Although ISO 14001 has been changed to its latest version in 2015, the 2004 version of the requirements empirically analyzed in this study are also part of the scope of ISO 14001: 2015 and are important parts of EMS requirements. 
The research presents important results to support the $\mathrm{CP}$ and EMS integration. The points reported in this research can contribute to the academic field of knowledge and to business and industrial practices.

A theoretical gap was covered at the frontier of knowledge that deals with the possibilities of integration between CP and ISO 14001 EMS. Based on empirical data, it was possible to identify the $\mathrm{CP}$ practices main contributions to the fulfillment of the ISO 14001 requirements.

In a practical and applied way, the results of this research serve as guidelines for companies to invest in $\mathrm{CP}$ practices as a way of maximizing their environmental performance and their conditions for implementing the EMS and achieving ISO 14001 certification.

However, limitations of this work should be pointed out. The sample of companies, although satisfactory for analysis, discussion and conclusions presented here is specific to a country, for a period of time and a limited number of individuals. Thus, the application of research is recommended in other countries, involving a greater number of companies to increase the potential of statistical inference and generalization of the results.

The literature shows that the size and business segment can influence the adoption of $\mathrm{CP}$ practices and the pursuit of ISO 14001. These influences were not measured and analyzed in this work and this approach is recommended for future studies. It is also suggested the use of other research methods, qualitative, in order to test the information in this research through a greater depth analysis.

Acknowledgements The authors gratefully acknowledge the financial aid provided by the Brazilian research funding agencies $\mathrm{CNPq}$ (National Council for Scientific and Technological Development, through Grant No. 479999/2009-0), CAPES (Coordination for higher Education Staff Development) and FAPESP (Sao Paulo Research Foundation).

\section{Appendix: Variables list}

\begin{tabular}{ll}
\hline Code & Variable \\
\hline B2 & Company size \\
B3 & Industrial classification \\
B4 & Market timing \\
B5 & Exportation percentage \\
B6 & Year of the first ISO 14001 certification \\
B7 & Certifications scope \\
B8 & Use of external consultancy for EMS implementation based \\
& on ISO 14001 \\
B9 & Time for implementation of the Environmental Management \\
& System based on ISO 14001
\end{tabular}

Code Variable

B10 Average investment necessary for the implementation of EMS based on ISO 14001

C1 CP adoption level by the organizations

$\mathrm{C} 2$ There is management commitment to the implementation of $\mathrm{CP}$

C3 There is definition of fixed and formal staff for the implementation of $\mathrm{CP}$

C4 There is establishment of goals and targets for CP

C5 There is a study to identify possible barriers for the implementation of $\mathrm{CP}$

C6 Flowchart of use in processes for identifying opportunities for implementation of $\mathrm{CP}$

C7 There is analysis of inputs and outputs of materials in production processes for identification of CP opportunities

C8 There is identification and priority ranking in the implementation of $\mathrm{CP}$

C9 There is preparation of mass balance in production processes for identification of $\mathrm{CP}$ opportunities

C10 There is assessment of the causes of the differences in the mass balance of the production processes

C11 There is identification and classification of CP opportunities

C12 There are established criteria for selection of CP options

C13 There are primary and general assessments of CP options

C14 There are technical assessments of CP options

C15 There are economical assessments of CP options

C16 There are environmental assessments of $\mathrm{CP}$ options

C17 There is selection of opportunities, according to the feasibility analysis of CP options

C18 A plan for implementation of CP options is prepared

C19 There is a systematic procedure for identification of CP opportunities

C20 Continuous actions of disposal or waste minimization in the production process are practiced

C21 Continued actions to reduce the use of inputs and raw materials at source

C22 Continuous actions of internal recycling in the production process occur

C23 Modifications in the product to minimize environmental impacts are made

C24 Modifications in the process or part of it to minimize environmental impacts are made

C25 Housekeeping is made

C26 There is substitution of raw materials to minimize environmental impacts

C27 Technology modifications are made to minimize environmental impacts

C28 There is a waste reuse system of production

C29 External recycling efforts are required to the production process

C30 There is monitoring of performance of CP shares after implementation

C31 There is support of CP shares (continuous improvement)

D1 General requirements (requirement 4.1) 


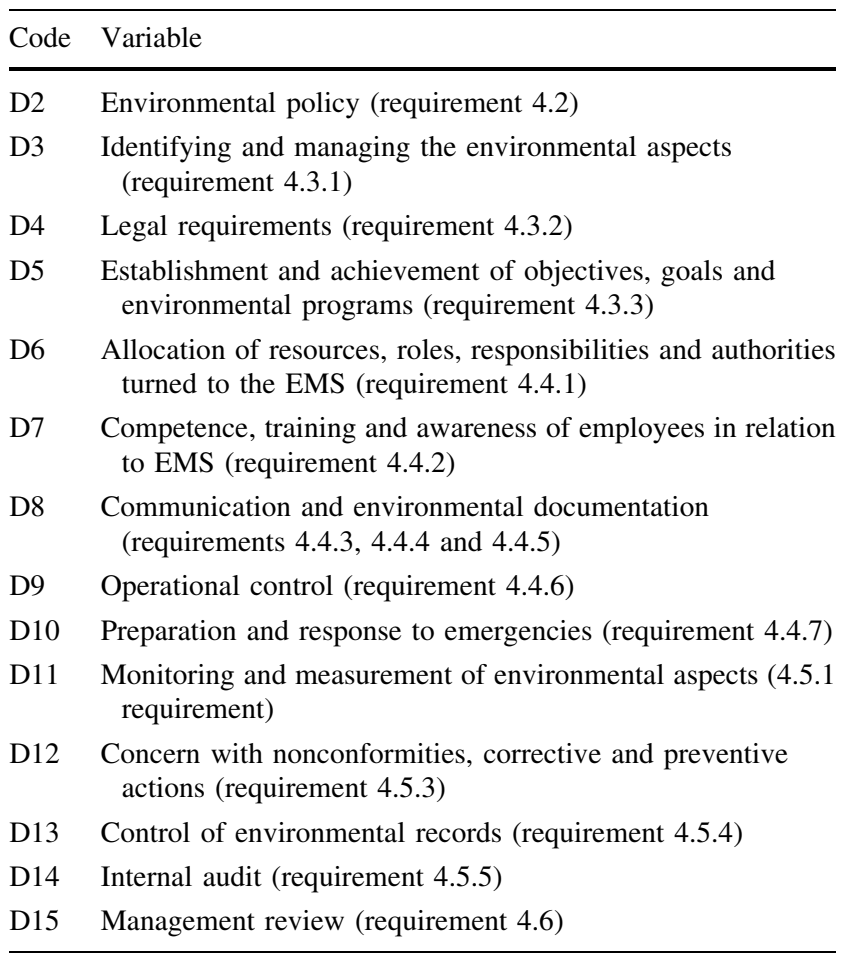

\section{References}

Arimura TH, Darnall N, Gangulli R, Katayama H (2016) The effect of ISO 14001 on environmental performance: resolving equivocal findings. J Environ Manag 166(15):556-566

Barrow CJ (2006) Environmental management for sustainable development. Routledge, New York

Beamon BM (1999) Designing the green supply chain. Logist Inf Manag 12(4):332-342

Campos LMS (2012) Environmental management systems (EMS) for small companies: a study in Southern Brazil. J Clean Prod $32: 141-148$
Cheremisinoff NP, Bendavid-Val A (2001) Green profits: the manager's handbook for ISO 14001 and pollution prevention. Butterworth-Heinemann, Boston

Florida R (1996) Lean and green: the move to environmentally conscious manufacturing. Calif Manag Rev 39:8-105

Forza C (2002) Survey research in operations management: a processbased perspective. Int J Oper Prod Manag 22(2):152-194

Hair FJ, Black WC, Babin B, Anderson RE, Tathan RL (2009) Análise multivariada de dados, $6^{\mathrm{a}}$ edn. Bookman, Porto Alegre

INMETRO - Instituto Nacional de Metrologia, Normalização e Qualidade Industrial (2012) Certified companies by ISO 14001. http://www.inmetro.gov.br. Accessed 10 Mar 2012

ISO 14001 (2004) Environmental management system: requirements with guidance for use. International Organization for Standardization, Geneva

ISO 14001 (2015) Environmental management system: requirements with guidance for use. International Organization for Standardization, Geneva

Jupp V (2006) The Sage dictionary of social research methods. Sage Publications, London

Khan Z (2008) Cleaner production: an economical option for ISO certification in developing countries. J Clean Prod 16:22-27

Montgomery DC, Runger GC (2003) Estatística Aplicada e Probabilidade para Engenheiros. Tradução Verônica Calado, 6th edn. LTC, Rio de Janeiro

Oliveira JA, Oliveira OJ, Ometto AR, Ferraudo AS, Salgado MH (2016) Environmental Management System ISO 14001 factors for promoting the adoption of cleaner production practices. J Clean Prod 133(1):1384-1394

Synodinos NE (2003) The art of questionnaire construction: some important considerations for manufacturing studies. Integr Manuf Syst 14(3):221-237

Tong O, Shao S, Zhang Y, Chen Y, Liu SL, Zhang SS (2012) An AHP-based water-conservation and waste-reduction indicator system for cleaner production of textile-printing industry in China and technique integration. Clean Technol Environ Policy 14(5):867-868

UNEP (1995) Cleaner production: a training resource package in Industry and Environment, Paris

UNEP/UNIDO (2004) Guidance manual: how to establish and operate cleaner production centres. UNIDO, Vienna

Xiong W, Xiong LLM (2010) Application of gray correlation analysis for cleaner production. Clean Technol Environ Policy 12(4):401-405 